\title{
Sensing small-scale structures in the troposphere with tomographic principles (IAG working group)
}

\section{Other Conference Item}

\section{Author(s):}

Möller, Gregor (D); Ao, Chi; Adavi, Zohreh; Brenot, Hugues; Sá, André; Hajj, George; Hanna, Natalia; Kitpracha, Chaiyaporn; Pottiaux, Eric; Rohm, Witold; Shehaj, Endrit; Trzcina, Estera; Wang, Kuo-Nung; Wilgan, Karina; Zhang, Kefei

Publication date:

2020-05

\section{Permanent link:}

https://doi.org/10.3929/ethz-b-000459448

\section{Rights / license:}

Creative Commons Attribution 4.0 International

Originally published in:

EGUsphere, https://doi.org/10.5194/egusphere-egu2020-8469 
EGU2020-8469

https://doi.org/10.5194/egusphere-egu2020-8469

EGU General Assembly 2020

(c) Author(s) 2021. This work is distributed under

the Creative Commons Attribution 4.0 License.

\section{Sensing small-scale structures in the troposphere with tomographic principles (IAG working group)}

Gregor Moeller ${ }^{1}$, Chi Ao ${ }^{2}$, Zohreh Adavi ${ }^{3}$, Hugues Brenot ${ }^{4}$, André Sá ${ }^{5}$, George Hajj ${ }^{2}$, Natalia Hanna ${ }^{3}$, Chaiyaporn Kitpracha ${ }^{6,9}$, Eric Pottiaux ${ }^{7}$, Witold Rohm ${ }^{8}$, Endrit Shehaj ${ }^{1}$, Estera Trzcina ${ }^{8}$, Kuo-Nung Wang ${ }^{2}$, Karina Wilgan ${ }^{6,9}$, and Kefei Zhang ${ }^{10}$

${ }^{1}$ ETH Zürich, Zürich, Switzerland

${ }^{2}$ Jet Propulsion Laboratory, California Institute of Technology, Pasadena, USA

${ }^{3} \mathrm{TU}$ Wien, Vienna, Austria

${ }^{4}$ Royal Belgian Institute for Space Aeronomy, Brussels, Belgium

${ }^{5}$ Polytechnic Institute of Guarda, Guarda, Portugal

${ }^{6}$ Technische Universität Berlin, Berlin, Germany

${ }^{7}$ Royal Observatory of Belgium, Brussels, Belgium

${ }^{8}$ Wroclaw University of Environmental and Life Sciences, Wroclaw, Poland

${ }^{9}$ German Research Centre for Geosciences, Potsdam, Germany

${ }^{10}$ Royal Melbourne Institute of Technology, Melbourne, Australia

Within the International Association of Geodesy (IAG), a new working group was formed with the intention to bring together researchers and professionals working on tomography-based concepts for sensing the neutral atmosphere with space-geodetic techniques. Hereby the focus lies on Global Navigation Satellite Systems (GNSS) but also on complementary observation techniques, like Interferometric Synthetic Aperature Radar (InSAR) or microwave radiometers, sensitive to the water vapor distribution in the lower atmosphere.

In the next four years (2019-2023), we will address current challenges in tropospheric tomography with focus on ground-based and space-based measurements, the combination of measurement techniques and the design of new observation concepts using tomographic principles. While geodetic GNSS networks are nowadays the backbone for troposphere tomography studies, further local densifications, e.g. at airports, cities or fundamental stations are necessary to achieve very fine spatial and temporal resolution. Besides, the combination of ground-based GNSS with other microwave techniques like radio occultation or InSAR seems to be beneficial due their complementary nature. Therefore, several further developments in the field of tropospheric tomography are required. This includes more dynamical tomography models - adaptable to varying input data, advanced ray-tracing algorithms for the reconstruction of space-based observations and the coordination of a benchmark campaign.

In this presentation, we will give an overview about the current challenges in tropospheric tomography and the objectives of working group. The latter will also include standards for data exchange and therefore, make tomographic products available for the assimilation into numerical 
weather prediction models but also for various other disciplines, which rely on accurate wet refractivities or derived products like tropospheric signal delays. 